\title{
Article
}

\section{Enhanced polysaccharide production in mycelium of Ganoderma atrum by solid-state fermentation}

\author{
Wen TC ${ }^{1}$, Kang $\mathrm{C}^{2}$, Wang $\mathrm{F}^{2}$, Liang $\mathrm{DQ}^{1}$ and Kang $\mathrm{JC}^{1^{*}}$ \\ ${ }^{1}$ The Engineering Research Center of Southwest Bio-Pharmaceutical Resources, Ministry of \\ Education, Guizhou University, Guiyang, 550025, Guizhou, China \\ ${ }^{2}$ Institute of Biology, Guizhou Academy of Sciences, Guiyang, 550009, Guizhou, China
}

Wen TC, Kang C, Wang F, Liang DQ, Kang JC. 2016 - Enhanced polysaccharide production in mycelium of Ganoderma atrum by solid-state fermentation. Mycosphere 7(6), 757-765, Doi 10.5943/mycosphere/7/6/5

\begin{abstract}
Polysaccharides are some of the most important bioactive compounds produced by species of Ganoderma. In this study, effects of ratio of material to water, the liquid supplement medium including carbon sources, nitrogen sources, and inorganic salts were also studied for the polysaccharide production in mycelium of Ganoderma atrum by solid-state fermentation. The seed of G. atrum was inoculated in $300 \mathrm{~mL}$ cylindrical glass bottles containing $60 \mathrm{~g}$ wheat grain at $28{ }^{\circ} \mathrm{C}$ for 20 days. One-factor-at-a time and an orthogonal design method were used to establish the optimal liquid supplement medium for maximum polysaccharide production in mycelium. The results showed that the highest polysaccharide production was achieved with ratio of material to water of 1:3, and the optimal liquid supplement medium contained $15 \mathrm{~g} / \mathrm{L}$ maltose, $10 \mathrm{~g} / \mathrm{L}$ peptone, $1 \mathrm{~g} / \mathrm{L} \mathrm{KCl}$ and $1.5 \mathrm{~g} / \mathrm{L} \mathrm{K}_{2} \mathrm{HPO}_{4} \cdot 3 \mathrm{H}_{2} \mathrm{O}$. The maximum polysaccharide yield in mycelium was 1.8 $\mathrm{mg} / \mathrm{g}$ on 20 days. This method first provides an effective way for obtaining polysaccharides in mycelium by solid-state fermentation in G. atrum. The strategies used in this study could be widely practical to other fermentation processes.
\end{abstract}

Key words - culture condition - mycelium polysaccharide - Orthogonal design - optimization

\section{Introduction}

Ganoderma (Polyporales, Basidiomycota) is one of the most important Traditional Chinese Medicinal mushrooms with a long history of use in the Orient (Gao et al. 2004, Zhang et al. 2014, Richter et al. 2015). Pharmaceutically active compounds in Ganoderma fruiting bodies and mycelium include adenosine, ganoderic acid, lectins, peptides, proteins, polysaccharides, terpenoids and sterols (Li \& Wang 2006, Zong et al. 2012, Nie et al. 2013, Zhang et al. 2014, Hapuarachchi et al. 2015). Polysaccharides and triterpenoids are the major source of biological activity and therapeutic (Liu \& Zhang 2007). Ganoderma has been used as a medicinal agent responsible for immunological regulation (Chen et al. 2014, Shi et al. 2014) and anticancer/antitumor (Li \& Wang 2006, Zhao et al. 2010, Zhang et al. 2013, Yu et al. 2014, Hapuarachchi et al. 2016), antioxidant (Chen et al. 2008), anti-fungus (Li et al. 2012), anti-hepatitis (Li \& Wang 2006), and anti-hyperlipidemia (Meng et al. 2011, Nie et al. 2013).

Submerged culture, solid-state fermentation (SSF) and stationary liquid fermentations are currently used for producing polysaccharides and triterpenoids from Ganoderma (Tang \& Zhong 2002b, Lee et al. 2003, Hsieh \& Yang 2004). Submerged fermentation was considered as a good 
method to increase mycelium, valuable metabolite, polysaccharide, and triterpenoid production (Liu \& Zhang 2007). In previous studies, ethyl acetate extracts from Eupolyphaga sinensis and Catharsius molossus, methanol, ethanol, 1-propanol, 2-propanol, whey permeate and corn oil, were added to the medium for improved polysaccharide production by G. lucidum (Liu \& Zhang 2007, Song et al. 2007, Huang et al. 2009).

In solid-state fermentations, it was considered that several months were needed to cultivate the Ganoderma fruiting bodies and that yield of biomass would be low (Douanla-Meli \& Langer 2009). Sources for solid substrate fermentations, such as grain, sawdust or wood, straw, and tea waste are abundant (Yang \& Liau 1998, Peksen \& Yakupoglu 2009), SSF has therefore become an attractive alternative to submerged culture fermentation for specific applications due to recent improvements in reactor designs (Couto \& Sanromán 2006).

In this study, we optimized fermentation medium nutrients to improve polysaccharide production in mycelium of G. atrum for the first time. This is one of the most important species of Ganoderma used for polysaccharide production. We used a one-factor-at-a time approach and an orthogonal design to improve yields. The effects of ratio of material to water, carbon sources, nitrogen sources, and inorganic salts were studied by solid-state fermentation in $300 \mathrm{~mL}$ cylindrical glass bottles.

\section{Materials \& Methods}

\section{Microorganism}

The strain of G. atrum was obtained from the culture collection of Huazhong Agricultural University (Hubei, China). The stock culture was maintained on potato dextrose agar (PDA) slants. The slants were inoculated with mycelia and incubated at $28{ }^{\circ} \mathrm{C}$ for 10 days.

\section{Seed culture on wheat by solid-state culture}

The seed medium was prepared by mixing $60 \mathrm{~g}$ of wheat (It was soaked in distilled water for $12 \mathrm{~h}$, and was drained for water on wheat grain surface) and $20 \mathrm{~mL}$ of distilled water in a 300 $\mathrm{mL}$ cylindrical glass bottle (inner diameter $7 \mathrm{~mm}$, height $12 \mathrm{~mm}$ ) and the bottle was sealed by film of polypropylene plastic. The medium was autoclaved for $30 \mathrm{~min}$ at $121{ }^{\circ} \mathrm{C}$. The medium was cooled to room temperature and inoculated with three discs $\left(1 \mathrm{~cm}^{2}\right)$ from the PDA slants and incubated at $28^{\circ} \mathrm{C}$ for 10 days in the dark.

\section{Solid-state fermentation for mycelium}

The fermentation medium was prepared by mixing $60 \mathrm{~g}$ of wheat (It was soaked in distilled water for $12 \mathrm{~h}$, and was drained for water on wheat grain surface) and the liquid supplement medium (carbon sources, nitrogen sources and inorganic salts) in a $300 \mathrm{~mL}$ cylindrical glass bottle (inner diameter $7 \mathrm{~mm}$, height $12 \mathrm{~mm}$ ) and the bottle was sealed by film of polypropylene plastic. The medium was autoclaved for $30 \mathrm{~min}$ at $121{ }^{\circ} \mathrm{C}$. The medium was cooled to room temperature and inoculated with 1 spoon wheat grain seed (The biomass weight of mycelium and wheat grain are $10 \mathrm{~g}$ ) and incubated at $28{ }^{\circ} \mathrm{C}$ for 20 days in the dark.

\section{Extraction of polysaccharide in G. atrum mycelium and assay}

The experiments were performed in $300 \mathrm{~mL}$ cylindrical glass bottles for 20 days. Total fermentation substrates containing $60 \mathrm{~g}$ wheat and mycelium of $G$. atrum were mixed with deionized water, and were extracted twice by hot water extraction for one hour each time. All extracts were filtered through gauze of six-layer and finally cooled. The cooled extracts were precipitated with two times volume of $95 \%(\mathrm{v} / \mathrm{v})$ ethanol overnight in refrigerator at $4{ }^{\circ} \mathrm{C}$. All precipitated samples were centrifuged at $2810 \times \mathrm{g}$ for $10 \mathrm{~min}$. The rough polysaccharide in mycelium at the bottom of tubes were collected, and dried to a constant dry weight at $60{ }^{\circ} \mathrm{C}$. Finally, the content of polysaccharide in mycelium was measured using a phenol sulfuric acid method (Douanla-Meli \& Langer 2009). 


\section{Orthogonal array for medium optimization}

In order to evaluate the influence of liquid supplement medium component (maltose, peptone, $\mathrm{KCl}$ and $\left.\mathrm{K}_{2} \mathrm{HPO}_{4} \cdot 3 \mathrm{H}_{2} \mathrm{O}\right)$ on mycelium polysaccharide production (MPP), $\mathrm{L}_{9}\left(3^{4}\right)$ orthogonal array was used to evaluate. The $\mathrm{L}_{9}\left(3^{4}\right)$ orthogonal array was selected to examine the effects of four factors on mycelium polysaccharide production (Table 1). The orthogonal arrays, data analysis and ANOVA were obtained using Design-Expert Version 8.0.5b software package (Stat-Ease Inc., Minneapolis, USA) based on the Taguchi method.

Table 1 Orthogonal experiment factors and levels.

\begin{tabular}{lllll}
\hline Factors & Symbols & $\begin{array}{l}\text { Level 1 } \\
(\mathrm{g} / \mathrm{L})\end{array}$ & $\begin{array}{l}\text { Level 2 } \\
(\mathrm{g} / \mathrm{L})\end{array}$ & $\begin{array}{l}\text { Level 3 } \\
(\mathrm{g} / \mathrm{L})\end{array}$ \\
\hline Maltose & $\mathrm{A}$ & 15 & 30 & 45 \\
Peptone & $\mathrm{B}$ & 10 & 20 & 30 \\
$\mathrm{KCl}$ & $\mathrm{C}$ & 0.5 & 1 & 1.5 \\
$\mathrm{~K}_{2} \mathrm{HPO}_{4} \cdot 3 \mathrm{H}_{2} \mathrm{O}$ & $\mathrm{D}$ & 0.5 & 1 & 1.5 \\
\hline
\end{tabular}

\section{Statistical analysis}

The dry weight of G. atrum mycelium polysaccharide (GAMP) production was expressed as means \pm SD. An Analysis of Variance (ANOVA) followed by Tukey's test was applied for multiple comparisons of significant analyses at $P<0.05$. Orthogonal design experiments and statistical data analyses were performed in Statistic Package for Social Science (SPSS) version 17.0 software packet.

\section{Results and discussion}

\section{Effects of ratio of material to water for polysaccharide}

In order to investigate the effect of ratio of material to water on the polysaccharide production in mycelium, different ratios of material to water $(1: 1-1: 5, \mathrm{~m} / \mathrm{v})$ were prepared in this study. The highest polysaccharide production of $1.48 \pm 0.10 \mathrm{mg} / \mathrm{g}$ was achieved with ratio of material to water of 1:3 (Fig. 1).

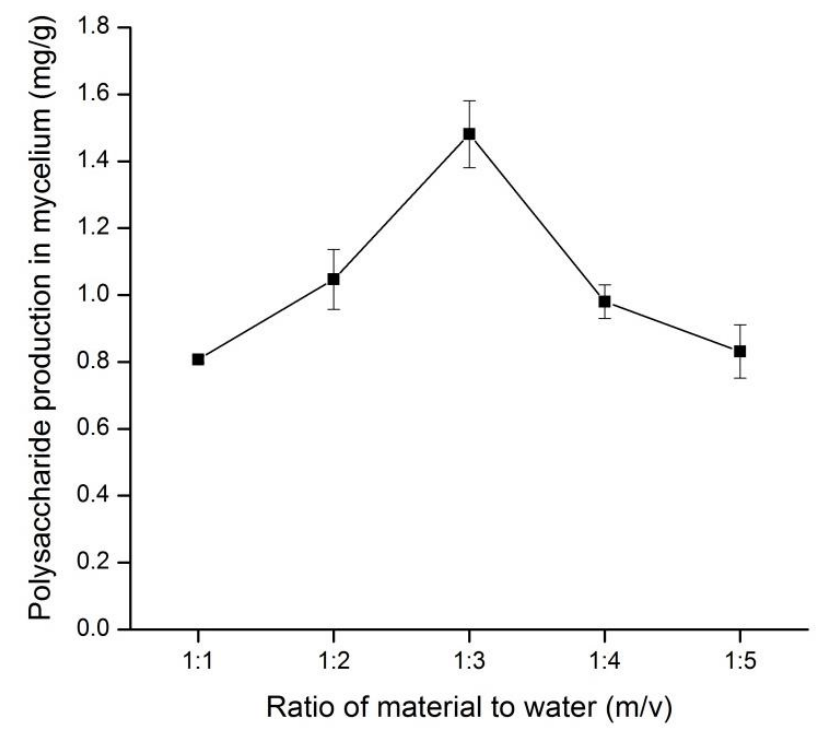

Fig. 1 - Effects of ratio of material to water on the polysaccharide production in G. atrum mycelium by solid-state fermentation. 


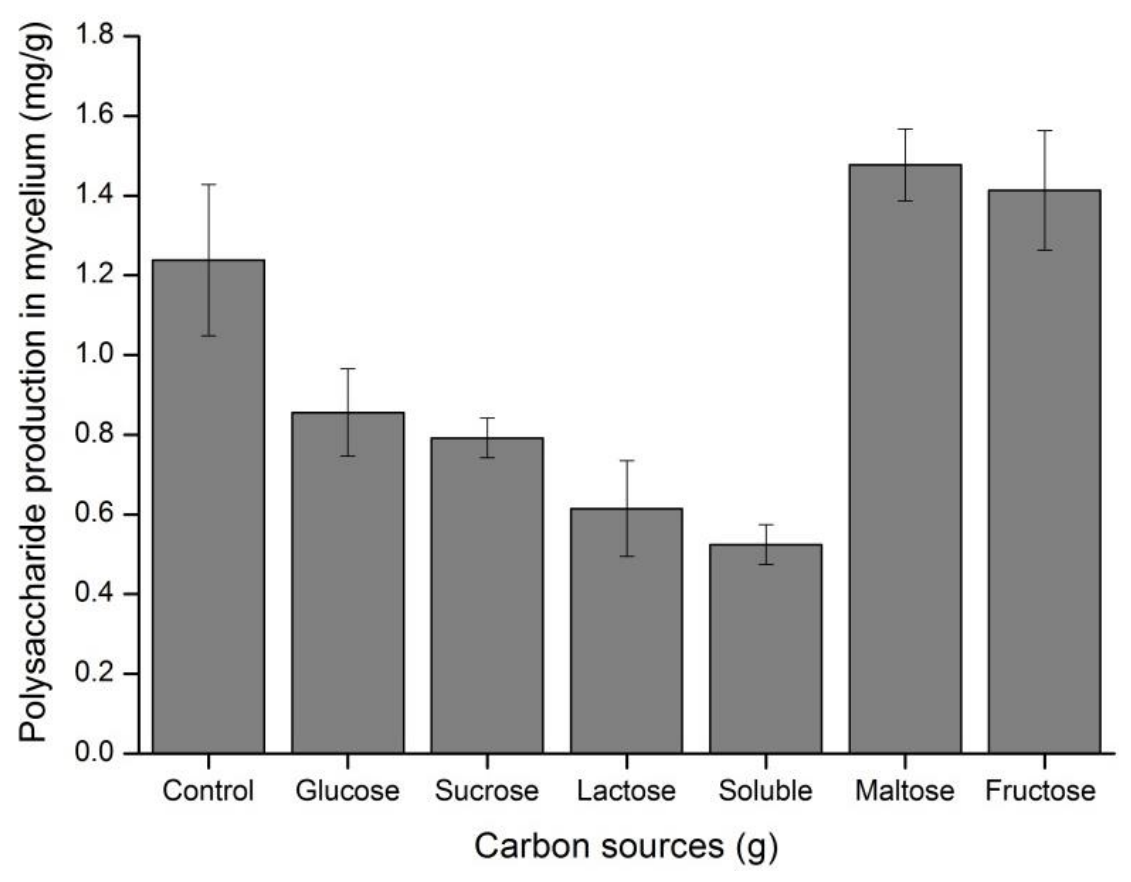

Fig. 2 - Effect of carbon sources on the polysaccharide production in G. atrum mycelium by solidstate fermentation.

\section{Effect of carbon sources}

To choose a suitable carbon source for polysaccharide in mycelium by G. atrum, six carbon sources including glucose, sucrose, lactose, soluble starch, maltose and fructose were prepared at concentrations of $30 \mathrm{~g} / \mathrm{L}$ in the basal medium. Maltose and fructose were the best carbon sources for polysaccharide production in mycelium (Fig. 2). Polysaccharide production in mycelium reached $1.48 \pm 0.09 \mathrm{mg} / \mathrm{g}$ with maltose and $1.413 \pm 0.15 \mathrm{mg} / \mathrm{g}$ with fructose. But there is a difference in this result compare to previous studies (Tang \& Zhong 2002a). Possible reasons are imparity of solid substrate or the cultivation method. Maltose was selected as the main carbon source in the remaining experiment.

\section{Effects of nitrogen sources}

To find a suitable nitrogen source for polysaccharide production in mycelium, we added various nitrogen sources (soybean meal, peptone, yeast extract, beef extract, $\mathrm{NH}_{4} \mathrm{NO}_{3}, \mathrm{NH}_{4} \mathrm{Cl}$ ) at a concentration of $20 \mathrm{~g} / \mathrm{L}$ to the nitrogen-free basal medium (Fig. 3). Peptone and yeast extract dramatically improved the mycelium growth rate of G. atrum, and the growth rate was faster when adding peptone as compared to yeast extract. Fermentation substrates of wheat grain were covered with mycelium of G. atrum at 15 days. However, growth rate of mycelium was slow when adding $\mathrm{NH}_{4} \mathrm{Cl}$ or $\mathrm{NH}_{4} \mathrm{NO}_{3}$. Organic nitrogen was advantageous to both growth and biosynthesis of metabolites. The result is consistent with the experimental data reported in other medicinal mushroom (Wen et al. 2008, Kang et al. 2012). The results suggested that maximum mycelium polysaccharide production of $1.39 \pm 0.08 \mathrm{mg} / \mathrm{g}$ was produced with peptone as a nitrogen source.

Inorganic ion is an important nutritional component in medium for mycelium growth (Bae, et al. 2000). In order to investigate the effect of inorganic salt for the polysaccharide production in mycelium by G. atrum, various inorganic salts $\left(\mathrm{MgSO}_{4} \cdot 7 \mathrm{H}_{2} \mathrm{O}, \mathrm{ZnSO}_{4}, \mathrm{KH}_{2} \mathrm{PO}_{4}, \mathrm{KCl}, \mathrm{CaSO}_{4} \cdot 2 \mathrm{H}_{2} \mathrm{O}\right.$, and $\mathrm{K}_{2} \mathrm{HPO}_{4} \cdot 3 \mathrm{H}_{2} \mathrm{O}$ ) were added to basal medium at a concentration of $1 \mathrm{~g} / \mathrm{L}$, individually. All inorganic salts improved polysaccharide production (Fig. 4). The highest polysaccharide production $(1.36 \pm 0.09 \mathrm{mg} / \mathrm{g})$ was observed in medium, when $\mathrm{K}_{2} \mathrm{HPO}_{4} \cdot 3 \mathrm{H}_{2} \mathrm{O}$ was used. At last, $\mathrm{K}_{2} \mathrm{HPO}_{4} \cdot 3 \mathrm{H}_{2} \mathrm{O}$ and $\mathrm{KCl}$ were recognized as the best two inorganic salts for mycelium polysaccharide production. 


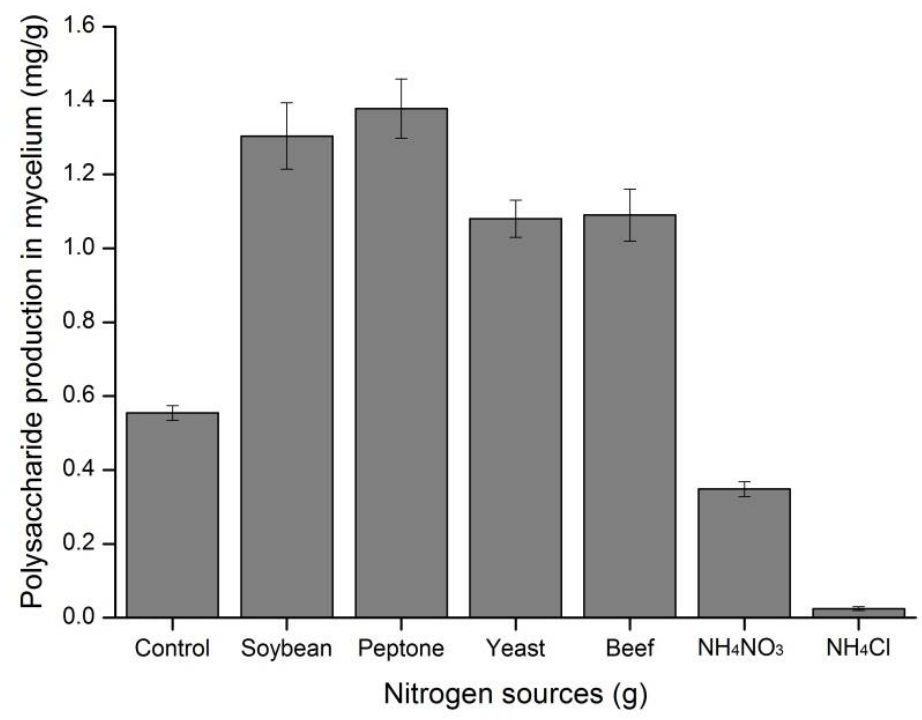

Fig. 3 - Effect of nitrogen sources on the polysaccharide production in G. atrum mycelium by solid-state fermentation.

\section{Effects of inorganic salt}

\section{Orthogonal experimental design}

To investigate the roles of different liquid supplement medium components and optimize their concentrations for polysaccharide production in mycelium, the orthogonal layout $\mathrm{L}_{9}\left(3^{4}\right)$ method was used. According to the above results achieved using the one-factor-at-a-time method, we selected and separated three levels as shown in Table 1. Table 2 shows the detailed experimental design and results. Nine experiments were carried out in triplicate. The experiment design and ANOVA for the experimental results obtained by SPSS Version software package, and optimal levels of each factor for obtaining higher polysaccharide production in mycelium are given in Table 2 and Table 3, respectively. And Fig. 5 shown the mycelium growth state for polysaccharide of $G$. atrum mycelium at 20 days by $\mathrm{L}_{9}\left(3^{4}\right)$ orthogonal design.

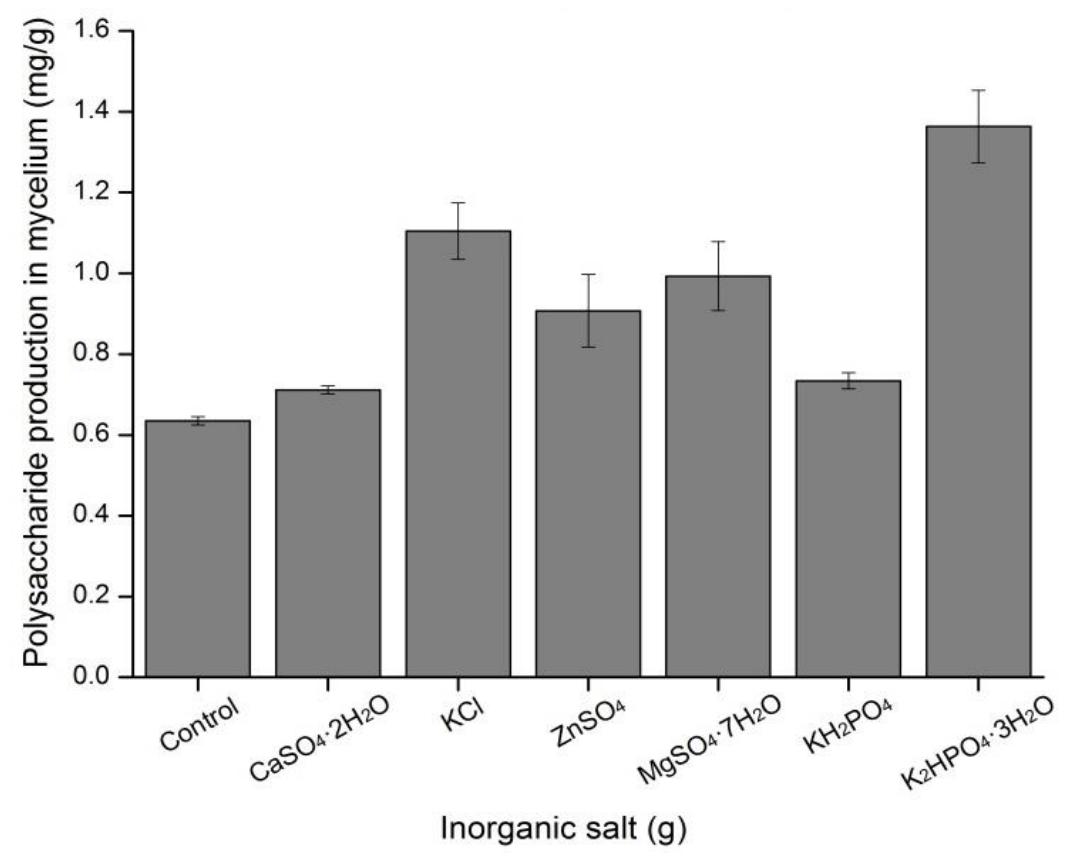

Fig. 4 - Effect of inorganic salt on the polysaccharide production in G. atrum mycelium by solidstate fermentation. 
Table 2 The $\mathrm{L}_{9}\left(3^{4}\right)$ orthogonal array applied for the polysaccharide production in G. atrum mycelium by solid-state fermentation.

\begin{tabular}{|c|c|c|c|c|c|c|c|c|}
\hline \multirow[t]{2}{*}{ Run } & \multicolumn{4}{|c|}{ Variables Code } & \multicolumn{4}{|c|}{$\begin{array}{l}\text { Polysaccharide production } \\
\mathrm{mg} / \mathrm{g}, \mathrm{n}=3 \text { ) }\end{array}$} \\
\hline & $A$ & $B$ & $C$ & $D$ & $Y_{1}$ & $Y_{2}$ & $Y_{3}$ & $\bar{Y}$ \\
\hline $1^{\mathrm{a}}$ & 1 & 1 & 1 & 1 & 1.48 & 1.40 & 1.41 & $1.43^{b}$ \\
\hline 2 & 1 & 2 & 2 & 2 & 1.08 & 1.05 & 1.20 & 1.11 \\
\hline 3 & 1 & 3 & 3 & 3 & 0.52 & 0.55 & 0.60 & 0.56 \\
\hline 4 & 2 & 1 & 2 & 3 & 1.55 & 1.46 & 1.60 & 1.54 \\
\hline 5 & 2 & 2 & 3 & 1 & 0.90 & 1.00 & 0.92 & 0.94 \\
\hline 6 & 2 & 3 & 1 & 2 & 0.57 & 0.58 & 0.60 & 0.58 \\
\hline 7 & 3 & 1 & 3 & 2 & 1.18 & 1.18 & 1.42 & 1.26 \\
\hline 8 & 3 & 2 & 1 & 3 & 1.12 & 0.78 & 0.87 & 0.92 \\
\hline 9 & 3 & 3 & 2 & 1 & 0.57 & 0.47 & 0.48 & 0.51 \\
\hline$K_{1}$ & $3.0963^{\mathrm{c}}$ & 4.2276 & 2.9367 & 2.8752 & & & & \\
\hline$K_{2}$ & 3.0588 & 2.9709 & 3.1524 & 2.9532 & & & & \\
\hline$K_{3}$ & 2.688 & 1.6443 & 2.754 & 3.0144 & & & & \\
\hline$k_{1}$ & $1.0321^{\mathrm{d}}$ & 1.4092 & 0.9789 & 0.9584 & & & & \\
\hline$k_{2}$ & 1.0196 & 0.9903 & 1.0508 & 0.9844 & & & & \\
\hline$k_{3}$ & 0.8960 & 0.5481 & 0.9180 & 1.0048 & & & & \\
\hline $\mathrm{R}$ & $0.1361^{\mathrm{e}}$ & 0.8611 & 0.1328 & 0.0463 & & & & \\
\hline $\begin{array}{l}\text { Optimal } \\
\text { level }\end{array}$ & 1 & 1 & 2 & 3 & & & & \\
\hline
\end{tabular}

a: The arrangements of column $A-D$ were decided by orthogonal design for $\mathrm{L}_{9}\left(3^{4}\right)$.

b: Average of triple determinations.

c: $K_{i}^{A}=\sum$ mycelia polysaccharide yield at $A_{i}$. Values are mean of triple determinations.

d: $k_{i}^{A}=K_{i}^{A} / 3$. Values are mean of triple determinations.

e : $R_{i}^{A}=\max \left\{K_{i}^{A}\right\}-\min \left\{k_{i}^{A}\right\}$. Values are mean of triple determinations.

Table 3 The ANOVA of the results of $\mathrm{L}_{9}\left(3^{4}\right)$ orthogonal design for the polysaccharide production in G. atrum mycelium.

\begin{tabular}{llllll}
\hline Source & Sum of quares & $\mathrm{df}$ & Mean Square & $F$-value & $p$-value Prob $>F$ \\
\hline$A$ & 0.102 & 2 & 0.051 & 6.40 & $0.008^{* *}$ \\
$B$ & 3.338 & 2 & 1.669 & 209.73 & $0.000^{* *}$ \\
$C$ & 0.080 & 2 & 0.040 & 5.00 & $0.019^{* *}$ \\
$D$ & 0.010 & 2 & 0.005 & 0.61 & 0.554 \\
Error & 0.143 & 18 & 0.008 & & \\
Total & 3.672 & 26 & & & \\
\hline
\end{tabular}

Pred- $R^{2}=0.961 ;$ Adj- $R^{2}=0.944 ;{ }^{* *} 1 \%$ significance level. 

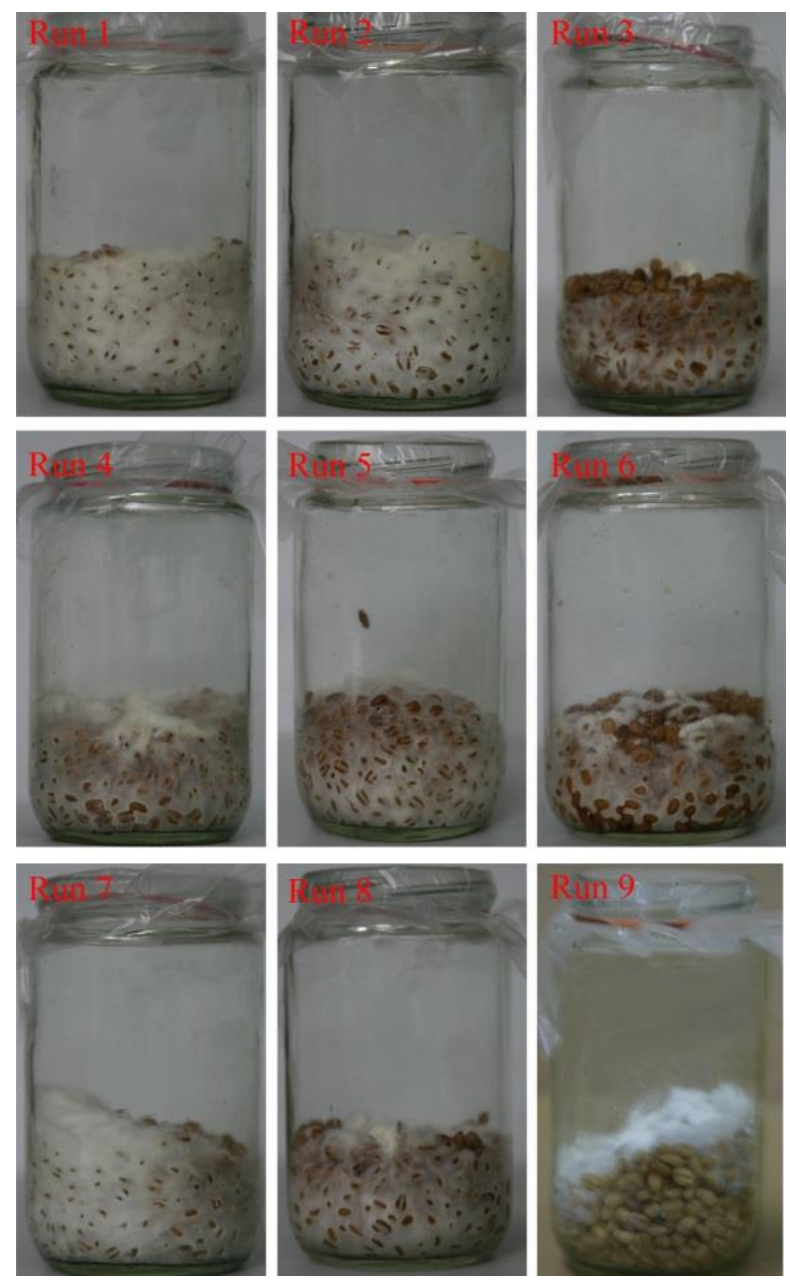

Fig. 5 - The mycelium growth state for polysaccharide of $G$. atrum mycelium at 20 days by $\mathrm{L}_{9}\left(3^{4}\right)$ orthogonal design.

As shown in Table 2, it is evident that maximum polysaccharide production of mycelium by G. atrum of $1.54 \mathrm{mg} / \mathrm{g}$ could be achieved using a combination of coded levels (A, maltose, level 1; $B$, peptone, level 1; $C, \mathrm{KCl}$, level 2; $D, \mathrm{~K}_{2} \mathrm{HPO}_{4} \cdot 3 \mathrm{H}_{2} \mathrm{O}$, level 3), and actual values for various factors were $15 \mathrm{~g} / \mathrm{L}$ maltose, $10 \mathrm{~g} / \mathrm{L}$ peptone, $1 \mathrm{~g} / \mathrm{L} \mathrm{KCl}, 1.5 \mathrm{~g} / \mathrm{L} \mathrm{K}_{2} \mathrm{HPO}_{4} \cdot 3 \mathrm{H}_{2} \mathrm{O}$, respectively.

According to the magnitude order of $\mathrm{R}$ (Max Dif), the order of effect of all factors on polysaccharide production could be determined, and was peptone $>$ maltose $>\mathrm{KCl}>$ $\mathrm{K}_{2} \mathrm{HPO}_{4} \cdot 3 \mathrm{H}_{2} \mathrm{O}$. Analysis of ANOVA (Table 3) showed that peptone, maltose, and $\mathrm{KCl}$ should be effective ingredients for improved polysaccharide production $(P<0.05)$. Nevertheless, $\mathrm{K}_{2} \mathrm{HPO}_{4} \cdot 3 \mathrm{H}_{2} \mathrm{O}$ was not significant $(P>0.05)$. Peptone was more significant than all other ingredients.

\section{Conclusions}

In this work, the one-factor-at-a time method and orthogonal design method were employed to establish the key factors and identify optimal culture conditions to improve the polysaccharide production in $G$. atrum mycelium by solid-state fermentation for the first time. The results showed that the highest polysaccharide production was achieved with ratio of material to water of $1: 3$, and the optimal liquid supplement medium contained $15 \mathrm{~g} / \mathrm{L}$ maltose, $10 \mathrm{~g} / \mathrm{L}$ peptone, $1 \mathrm{~g} / \mathrm{L} \mathrm{KCl}$ and $1.5 \mathrm{~g} / \mathrm{L} \mathrm{K}_{2} \mathrm{HPO}_{4} \cdot 3 \mathrm{H}_{2} \mathrm{O}$. The maximum polysaccharide yield in mycelium was $1.8 \mathrm{mg} / \mathrm{g}$ on 20 days. This method first provides an effective way for increasing polysaccharides production by solidstate fermentation in G. atrum. The strategies used in this study could be widely practical to other fermentation processes. 


\section{Acknowledgements}

This work was supported by the project of Karst Science Research Center of National Natural Science Foundation of China - the People's Government of Guizhou Province, the Science Foundation of Guizhou University (No. 201309) and the Youth Foundation of Guizhou Academy of Sciences (No. 201407).

\section{References}

Bae JT, Sinha J, Park JP, Song CH, Yun JW. 2000 - Optimization of submerged culture conditions for exo-biopolymer production by Paecilomyces japonica. Journal of Microbiology and Biotechnology 10(4), 482-487.

Chen Y, Xie MY, Nie SP, Li C, Wang YX. 2008 - Purification, composition analysis and antioxidant activity of a polysaccharide from the fruiting bodies of Ganoderma atrum. Food Chemistry 107(1), 231-241, Doi 10.1016/j.foodchem.2007.08.021.

Chen Y, Zhang H, Wang YX, Nie SP, Li C, Xie MY. 2014 - Acetylation and carboxymethylation of the polysaccharide from Ganoderma atrum and their antioxidant and immunomodulating activities. Food Chemistry 156, 279-288, Doi 10.1016/j.foodchem.2014.01.111.

Couto SR, Sanromán MA. 2006 - Application of solid-state fermentation to food industry - a review. Journal of Food Engineering 76(3), 291-302, Doi 10.1016/j.jfoodeng.2005.05.022.

Douanla-Meli C, Langer E. 2009 - Ganoderma carocalcareus sp. nov., with crumbly-friable context parasite to saprobe on Anthocleista nobilis and its phylogenetic relationship in $G$. resinaceum group. Mycological Progress 8(2), 145-155, Doi 10.1007/s11557-009-0586-4.

Gao YH, Chan E, Zhou SF. 2004 - Immunomodulating activities of Ganoderma, a mushroom with medicinal properties. Food Reviews International 20(2), 123-161, Doi 10.1081/FRI120037158.

Hapuarachchi KK, Wen TC, Deng CY, Kang JC, Hyde KD. 2015 - Mycosphere Essays 1: Taxonomic confusion in the Ganoderma lucidum species complex. Mycosphere 6(5), 542559, Doi 10.5943/mycosphere/6/5/4.

Hapuarachchi KK, Wen TC, Jeewon R, Wu XL, Kang JC, Hyde KD. 2016 - Mycosphere Essays 7: Ganoderma lucidum - are the beneficial anti-cancer properties substantiated? Mycosphere 7(3), 305-332, Doi 10.5943/mycosphere/7/3/6.

Hsieh C, Yang FC. 2004 - Reusing soy residue for the solid-state fermentation of Ganoderma lucidum. Bioresource Technology 91(1), 105-109, Doi 10.1016/S0960-8524(03)00157-3.

Huang HC, Chen CI, Hung C, Liu YC. 2009 - Experimental analysis of the oil addition effect on mycelia and polysaccharide productions in Ganoderma lucidum submerged culture. Bioprocess and Biosystems Engineering 32(2), 217-224, Doi 10.1007/s00449-008-0239-z.

Kang C, Wen TC, Kang JC, Qian YX, Lei BX. 2012 - Effcts of additives and different culture conditions on cordycepin production by the medicinal fungus Cordyceps militaris (in Chinese). Mycosystem 31(3), 389-397,

Lee HY, Song MY, Hwang SH. 2003 - Optimizing bioconversion of deproteinated cheese whey to mycelia of Ganoderma lucidum. Process Biochemistry 38(12), 1685-1693, Doi 10.1016/S0032-9592(02)00259-5.

Li WJ, Nie SP, Liu XZ, Zhang H, Yang Y, Yu Q, Xie MY. 2012 - Antimicrobial properties, antioxidant activity and cytotoxicity of ethanol-soluble acidic components from Ganoderma atrum. Food and Chemical Toxicology 50(3), 689-694, Doi 10.1016/j.fct.2011.12.011.

Li YQ, Wang SF. 2006 - Anti-hepatitis B activities of ganoderic acid from Ganoderma lucidum. Biotechnology Letters 28(11), 837-841, Doi 10.1007/s10529-006-9007-9.

Liu GQ, Zhang KC. 2007 - Enhancement of polysaccharides production in Ganoderma lucidum by the addition of ethyl acetate extracts from Eupolyphaga sinensis and Catharsius molossus. Applied Microbiology and Biotechnology 74(3), 572-577, Doi 10.1007/s00253-006-07097.

Meng GL, Zhu HY, Yang SJ, Wu F, Zheng HH, Chen E, Xu JL. 2011 - Attenuating effects of 
Ganoderma lucidum polysaccharides on myocardial collagen cross-linking relates to advanced glycation end product and antioxidant enzymes in high-fat-diet and streptozotocin-induced diabetic rats. Carbohydrate Polymers 84(1), 180-185, Doi 10.1016/j.carbpol.2010.11.016.

Nie SP, Zhang H, Li WJ, Xie MY. 2013 - Current development of polysaccharides from Ganoderma: isolation, structure and bioactivities. Bioactive Carbohydrates and Dietary Fibre 1(1), 10-20, Doi 10.1016/j.bcdf.2013.01.001.

Peksen A, Yakupoglu G. 2009 - Tea waste as a supplement for the cultivation of Ganoderma lucidum. World Journal of Microbiology and Biotechnology 25(4), 611-618, Doi 10.1007/s11274-008-9931-z.

Richter C, Wittstein K, Kirk MP, Stadler M. 2015 - An assessment of the taxonomy and chemotaxonomy of Ganoderma. Fungal Diversity 71, 1-15, Doi 10.1007/s13225-0140313-6.

Shi M, Yang YN, Hu XS, Zhang ZY. 2014 - Effect of ultrasonic extraction conditions on antioxidative and immunomodulatory activities of a Ganoderma lucidum polysaccharide originated from fermented soybean curd residue. Food Chemistry 155, 50-56, Doi 10.1016/j.foodchem.2014.01.037.

Song M, Kim N, Lee S. Hwang S. 2007 - Use of whey permeate for cultivating Ganoderma lucidum mycelia. Journal of Dairy Science 90(5), 2141-2146, Doi 10.3168/jds.2006-690.

Tang YJ, Zhong JJ. 2002a - Exopolysaccharide biosynthesis and related enzyme activities of the medicinal fungus, Ganoderma lucidum, grown on lactose in a bioreactor. Biotechnology Letters 24(12), 1023-1026, Doi 10.1023/A:1015677313598.

Tang YJ, Zhong JJ. 2002b - Fed-batch fermentation of Ganoderma lucidum for hyperproduction of polysaccharide and ganoderic acid. Enzyme and Microbial Technology 31 (1), 20-28, Doi 10.1016/S0141-0229(02)00066-2.

Wen TC, Kang JC, Lei BX, Li GR, He J. 2008 - Effects of different solid culture condition on fruit body and cordycepin output of Cordyceps militaris (in Chinese). Guizhou Agricultural Sciences 4(36), 92-94,

Yang FC, Liau CB. 1998 - Effects of cultivating conditions on the mycelial growth of Ganoderma lucidum in submerged flask cultures. Bioprocess Engineering 19(3), 233-236, Doi 10.1007/PL00009014.

Yu Q, Nie SP, Wang JQ, Yin PF, Huang DF, Li WJ, Xie MY. 2014 - Toll-like receptor 4-mediated ROS signaling pathway involved in Ganoderma atrum polysaccharide-induced tumor necrosis factor- $\alpha$ secretion during macrophage activation. Food and Chemical Toxicology 66, 14-22, Doi 10.1016/j.fct.2014.01.018.

Zhang H, Nie SP, Yin JY, Wang YX, Xie MY. 2014 - Structural characterization of a heterogalactan purified from fruiting bodies of Ganoderma atrum. Food Hydrocolloids 36, 339-347, Doi 10.1016/j.foodhyd.2013.08.029.

Zhang SS, Nie SP, Huang DF, Li WJ, Xie MY. 2013 - Immunomodulatory effect of Ganoderma atrum polysaccharide on CT26 tumor-bearing mice. Food Chemistry 136 (3), 1213-1219, Doi 10.1016/j.foodchem.2012.08.090.

Zhao LY, Dong YH, Chen GT, Hu QH. 2010 - Extraction, purification, characterization and antitumor activity of polysaccharides from Ganoderma lucidum. Carbohydrate Polymers 80 (3), 783-789, Doi 10.1016/j.carbpol.2009.12.02.

Zong AZ, Cao HZ, Wang FS. 2012 - Anticancer polysaccharides from natural resources: A review of recent research. Carbohydrate Polymers 90(4), 1395-1410, Doi 10.1016/j.carbpol.2012.07.026. 